\title{
Differences in ruminal temperature between pregnant and non-pregnant Korean cattle
}

\author{
Dae Hyun Kim ${ }^{1,4}$, Jae Jung $\mathrm{Ha}^{1}$, Jun Koo $\mathrm{Yi}^{1}$, Byung Ki Kim${ }^{1}$, Woo-Sung Kwon ${ }^{2}$, Bong-Hae $\mathrm{Ye}^{3}$, \\ Seung Ho $\mathrm{Kim}^{4}$ and Yoonseok Lee ${ }^{4,5, *}$ \\ ${ }^{1}$ Livestock Research Institute, Yeongju 36052, Korea \\ ${ }^{2}$ Department of Animal Science and Biotechnology, Kyungpook National University, Sangju 37224, Korea \\ ${ }^{3}$ Division of Livestock Policy, Province of Gyeongsangbuk-Do, Andong 36759, Korea \\ ${ }^{4}$ Department of Biotechnology, College of Agriculture \& Life Science, Hankyong National University, Anseong 17579, Korea \\ ${ }^{5}$ Center for Genetic Information, College of Agriculture \& Life Science, Hankyong National University, Anseong 17579, Korea
}

Received January 17, 2021

Revised March 12, 2021

Accepted March 12, 2021

*Correspondence

Yoonseok Lee

E-mail: yoonseok95@hknu.ac.kr

ORCID

https://orcid.org/0000-0003-4803-5192

\begin{abstract}
In recent years, various methods of measuring body temperature have been developed using wireless biosensors to facilitate an early detection of pregnancy and parturition in cows. However, there are no studies on real-time monitoring of cattle body temperature throughout pregnancy. Therefore, we investigated the daily mean ruminal temperature in pregnant cows throughout pregnancy using a ruminal bio-capsule sensor and then evaluated the temperature variation between pregnant and non-pregnant cows. In pregnant cows, the mean and standard deviation of ruminal temperature was $38.86 \pm 0.17^{\circ} \mathrm{C}$. Ruminal temperature in pregnant cows slowly decreased until 180 to 190 days after artificial insemination and after that, the temperature increased dramatically until just before parturition. Furthermore, the means ruminal temperature was significantly different between pregnant and nonpregnant cows. The mean and standard deviation of ruminal temperature were as follows: $38.68 \pm 0.01^{\circ} \mathrm{C}$ from days 80 to $100,38.78 \pm 0.02^{\circ} \mathrm{C}$ from days 145 to 165 , $38.99 \pm 0.45^{\circ} \mathrm{C}$ from days 200 to $220,39.14 \pm 0.38^{\circ} \mathrm{C}$ from days 250 to 270 before parturition. Therefore, our results could provide useful data for early detection of pregnancy and parturition in Korean cows.
\end{abstract}

Keywords: Korean cattle, pregnant cow, ruminal bio-capsule sensor, ruminal temperature

\section{INTRODUCTION}

Recently, Information \& communications technology (ICT) has been used to increase reproductive performance, and improve breeding management and disease detection in the livestock industry (Cooper-Prado et al., 2011; Lee et al., 2016; Sakatani et al., 2018; Higaki et al., 2019). Early detection of estrus and pregnancy in breeding cows is an important factor influencing reproductive performance. Currently, there are many physiological in- dicators to detect the occurrence of estrus and pregnancy. Among these indicators, several studies have reported that changing body temperature in cows is associated with reproductive performance. A study showed that body temperature increased in pregnant cows and changing of body temperature highly correlates with physiological mechanisms (Suthar et al., 2012). Furthermore, body temperature in lactating dairy cattle is higher than that in pregnant cows because of metabolic heat generation. It was shown that body temperature in pregnant cows was 
higher than that in non-pregnant cows during fertilization after artificial insemination (Gil et al., 2001). Vaginal temperature in pregnant dairy cows changes depending on the stage of pregnancy (Scanavez et al., 2017). At pregnancy day 180, vaginal and rectal temperatures in pregnant cows were relatively higher than that in nonpregnant cows, and these temperatures immediately decreased before parturition (Burfeind et al., 2011; CooperPrado et al., 2011; Suthar et al., 2012; Ricci et al., 2018).

Recently, a technology has been developed to detect temperature changes in real-time by inserting a sensor into the rumen of a cow through the bolus system. Various studies using implantable sensors to detect change in milk production, ruminal $\mathrm{pH}$, feed intake rate, and vaccination have been conducted (Gasteiner et al., 2012; Gasteiner et al., 2015; Kim et al., 2017a; Ammer et al., 2018; Villot et al., 2018).

Use of thermometers, the most common method of measuring core body temperature, is limited and cannot be used to measure body temperature in real-time. Several wearable sensors have been developed for real-time monitoring of cattle body temperature (Gasteiner et al., 2012; Gasteiner et al., 2015; Kim et al., 2017a; Ammer et al., 2018).

Therefore, the aim of this study was to record the daily body temperature throughout the pregnancy period using a ruminal wearable sensor, and to investigate the differences in body temperature between pregnant and nonpregnant cows.

\section{MATERIALS AND METHODS}

\section{Animals and management}

The animal experiment was approved by the IACUC (Institutional Animal Care and Use Committee) of the Gyeongsangbuk-do Livestock Research Institute and all applicable national laws and policies regarding the care and use of animals were performed during the experi- ment. One hundred twelve mature Hanwoo cows (37 pregnant and 75 non-pregnant cows) were included in the study. During the experiment, cows were housed in a stanchion barn with sufficient space and were given feed according to the Korean feeding standards program. Rice straw, mineral blocks, and water were fed ad libitum. The breeding management information on the experimental animals by group used in this study are shown in Table 1 . No abnormalities in the ovaries and uterus were found through ultrasound examination.

\section{Real-time measurement of ruminal temperature using wearable bio-capsule sensor}

In order to monitor ruminal temperature in real-time, cows were orally administered the ruminal wireless biocapsule sensor (LiveCare, UlikeKorea, Korea). Recently, this sensor has been validated in a dairy cattle experiment with rumen-cannulated cows (Kim et al., 2017b). The sensor measured ruminal temperature every $10 \mathrm{~min}$ and transmitted the data in real-time to a basis station using the LiveCare system. The size of the sensor was $125 \mathrm{~mm}$ in length with a diameter of $36 \mathrm{~mm}$ and the weight was $200 \mathrm{~g}$ when the battery was inserted. The ruminal temperature was collected according to the method reported by Kim et al., 2017b.

\section{Detection of pregnancy}

Pregnancy was detected at 40 days after artificial insemination using transrectal ultrasonography (HONDA HS$101 \mathrm{~V}$, HONDA, Japan) and reconfirmed at days 100 and 200 of pregnancy.

\section{Statistical analysis}

Data on ruminal temperature from the ruminal wireless bio-capsule sensors were downloaded into Excel spreadsheets. The data were analyzed to determine the pattern of ruminal temperature in cows and compared between pregnant and non-pregnant cows using the 'ggplot' pack-

Table 1. The breeding management information of pregnant and non-pregnant cows

\begin{tabular}{lcccc}
\hline \multirow{2}{*}{ Group } & \multirow{2}{*}{ No. of cows } & & Mean \pm SD* & \\
\cline { 3 - 5 } & & Ruminal temperature & Month of breeding & Parity \\
\hline Pregnant cows & 37 & $38.86 \pm 0.17$ & $34.0 \pm 1.84$ & $1.2 \pm 0.14$ \\
Non-pregnant cows & 75 & $38.72 \pm 0.08$ & $34.3 \pm 2.39$ & $0.9 \pm 0.12$ \\
Total & 112 & $38.76 \pm 0.06$ & $34.1 \pm 1.45$ & $1.1 \pm 0.10$ \\
\hline
\end{tabular}

\footnotetext{
*Standard deviation.
} 
age of the R program (version: 3.6.2, Foundation for Statistical Computing, Vienna, Austria). Ruminal temperature $<37.5^{\circ} \mathrm{C}$ were considered as a consequence of water consumption (Bewley et al., 2008; Cooper-Prado et al., 2011) and excluded from analyses.

The daily mean ruminal temperature was calculated throughout pregnancy. Furthermore, for comparison of body temperature, the means were calculated at four different periods of pregnancy: days 80 to 100 , days 145 to 165 , days 200 to 220 , and days 250 to 270 . So, the daily mean ruminal temperature at four periods was compared by one-way ANOVA and Tukey's HSD tests. The results were reported as the mean \pm standard deviation (SD) and differences with $p<0.05$ were considered significant.

\section{RESULTS}

\section{Pattern of the daily mean ruminal temperature in Hanwoo cow}

We determined the daily mean ruminal temperature for the entire period of pregnancy using data collected from wireless bio-capsule sensors. The pattern of the daily mean ruminal temperature in cows $(n=112)$ is presented in Fig. 1. The body temperature was measured every 10 min using a wireless bio-capsule sensor and then the daily mean was calculated.

As shown in Fig. 1, the mean and standard deviation of ruminal temperature was $38.76 \pm 0.06^{\circ} \mathrm{C}$, and the maxi- mal and minimal temperatures were $39.05^{\circ} \mathrm{C}$ and $38.61^{\circ} \mathrm{C}$, respectively. All cows were vaccinated with FMD (Foot and Mouth Disease) vaccine on February 1, 2019. After FMD vaccination, a rapidly increasing ruminal temperature was confirmed in all cows because of inflammation and acutephase reaction. The daily mean and standard deviation of ruminal temperature in pregnant cows was $38.86 \pm 0.17^{\circ} \mathrm{C}$ and that in non-pregnant cows was $38.72 \pm 0.08^{\circ} \mathrm{C}$.

\section{Comparison of ruminal temperature in pregnant cows with that in non-pregnant cows}

Differences in ruminal temperature between pregnant and non-pregnant cows is shown in Fig. 2. In this study, since the gestation period was different in all pregnant cows, gestation periods were sorted by parturition day using the R program.

As shown in Fig. 2, the mean ruminal temperature in pregnant cows was gradually decreased compared to nonpregnant cows at 245 days after artificial insemination. In addition, the mean ruminal temperature between pregnant and non-pregnant cows showed the highest difference at 100 days before parturition. Since then, the mean ruminal temperature in pregnant and non-pregnant cows was similarly maintained from 180 to 190 days before parturition $(p<0.05)$. The mean ruminal temperature in pregnant cows was increased compared with non-pregnant cows until 190 to 280 days just before parturition.

Overall, we found that the mean ruminal temperature

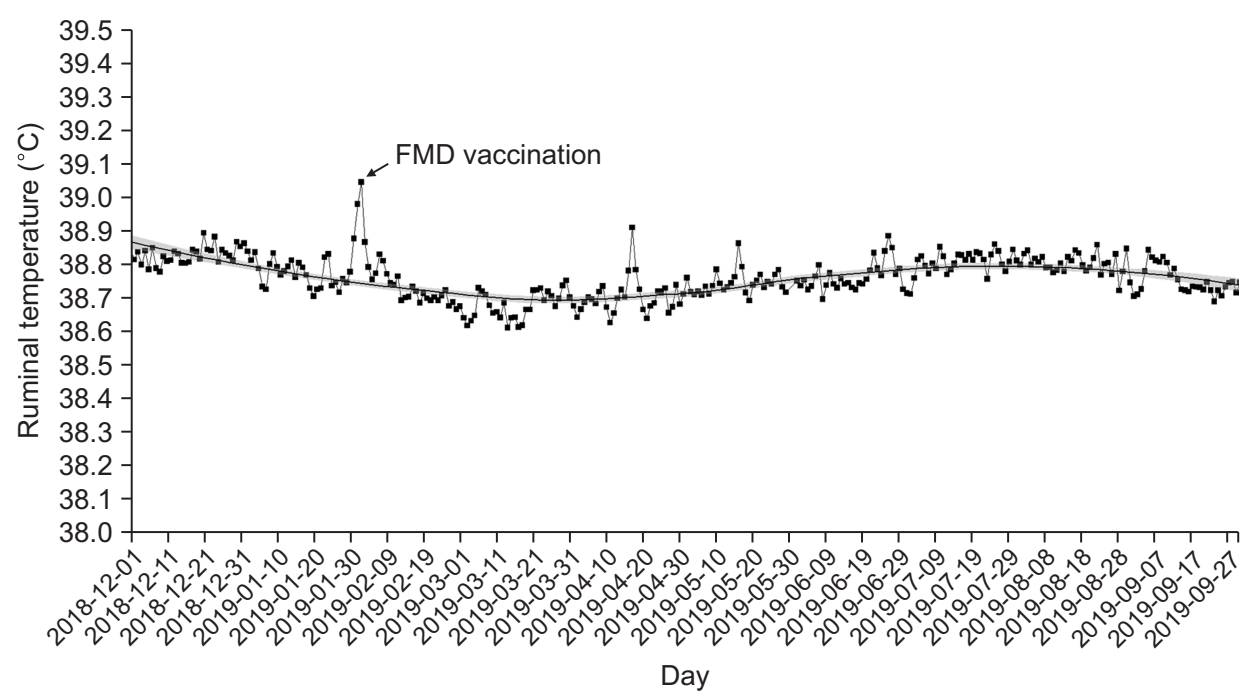

Fig. 1. The pattern of daily mean of ruminal temperature in Hanwoo cows $(n=112)$. The mean and standard deviation of ruminal temperature. The black line connected by the black round dot $(\bullet)$ represents the average daily ruminal temperature. Black lines with shades depict polynomial regression lines. The black diagonal line indicates when the FMD vaccine was administered. 


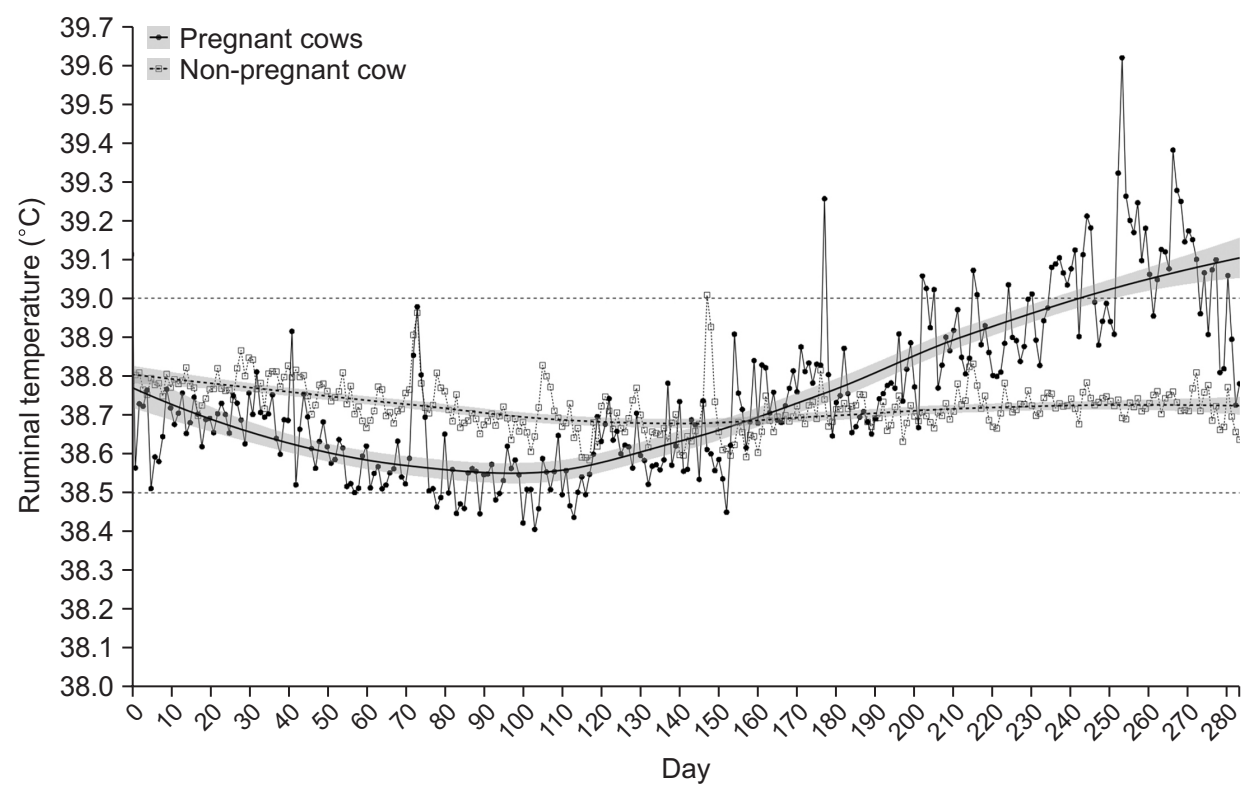

Fig. 2. The difference in the daily pattern of ruminal temperature between pregnant and non-pregnant cows throughout pregnancy. The mean and standard deviation of ruminal temperature. The black line connected by the black round dot represents the average daily ruminal temperature in pregnant cows. The dashed line and solid line represent \pm 2 standard deviation and average temperature in non-pregnant cows. Shaded black lines and dotted lines represent polynomial regression lines. The black diagonal line indicates when the FMD vaccine was administered. Thick horizontal black bars represent mean ruminal temperatures at four different periods: days 80 to 100 (I), days 145 to 165 (II), days 200 to 220 (III), and days 250 to 270 (IV). Means without a common letter represent significant differences ( $p<0.05)$.

Table 2. The probability value of ruminal temperature in pregnant and non-pregnant cows at four periods after artificial insemination

\begin{tabular}{lcc}
\hline \multirow{2}{*}{$\begin{array}{c}\text { Day after artificial } \\
\text { insemination }\end{array}$} & \multicolumn{2}{c}{ Ruminal temperature (Mean \pm SD* $^{*}$ ) } \\
\cline { 2 - 3 } & Pregnant & Non-pregnant \\
\hline $80-100$ & $38.68^{\mathrm{a}} \pm 0.01^{\mathrm{a}}$ & $38.68 \pm 0.04$ \\
$145-165$ & $38.78^{\mathrm{b}} \pm 0.02^{\mathrm{b}}$ & $38.69 \pm 0.04$ \\
$200-220$ & $38.99^{\mathrm{c}} \pm 0.45^{\mathrm{c}}$ & $38.71 \pm 0.05$ \\
$250-270$ & $39.14^{\mathrm{d}} \pm 0.38^{\mathrm{d}}$ & $38.66 \pm 0.03$ \\
$p^{-v a l u e}$ & 0.000 & 0.151 \\
\hline
\end{tabular}

*Standard deviation.

a,b,c,d Means with different letters are significantly different at $p<0.05$.

between pregnant and non-pregnant cows for four different pregnancy periods was significantly different. The probability value, mean and standard deviation of ruminal temperature in pregnant and non-pregnant cows is shown in Table 2. The mean and standard deviation were as follows: $38.672 \pm 0.007^{\circ} \mathrm{C}$ from days 80 to $100,38.785 \pm$ $0.010^{\circ} \mathrm{C}$ from days 145 to $165,39.006 \pm 0.010^{\circ} \mathrm{C}$ from days 200 to 220 , and $39.126 \pm 0.010^{\circ} \mathrm{C}$ from days 250 to 270 after artificial insemination.

\section{DISCUSSION}

In this study, we investigated the daily variation in mean ruminal temperature in pregnant cows throughout pregnancy using a wireless bio-capsule sensor system, and then evaluated the differences in ruminal temperature between pregnant and non-pregnant cows. Our results showed that the ruminal temperature in pregnant cows gradually decreased at 180-190 days after artificial insemination and since then, it dramatically increased until just before parturition.

However, the results were inconsistent with previous several studies. Gil et al. (2001) suggested that the mean rectal temperature in pregnant cows $\left(39.09 \pm 0.22^{\circ} \mathrm{C}\right)$ was higher than that in non-pregnant cows $\left(38.63 \pm 0.1{ }^{\circ} \mathrm{C}\right)$ at 5-12 days of gestation. This could be due to the differences in temperature measurement sites described by Lee et al. (2016).

In addition, at 180 days after artificial insemination, the vaginal and rectal temperatures in pregnant cows were increased by $0.3^{\circ} \mathrm{C}$ and $0.2^{\circ} \mathrm{C}$, respectively than that in non-pregnant cows, although these differences were not significant (Suthar et al., 2012). Although the observed ruminal temperature in pregnant cows was higher than 
that in non-pregnant cows from days 180 to 190 before parturition, the estimated mean between pregnant and non-pregnant cows was similar.

Notably, our study identified that ruminal temperature in pregnant cows was gradually increased from day 180 to just before parturition. During the period from day 180 to just before parturition, the increase in ruminal temperature led to an increase in the level of progesterone, which in turn increased the core temperature due to its thermogenic effect (Cooper-Prado et al., 2011).

Furthermore, the ruminal temperature in pregnant cows during the luteal phase was higher than that in nonpregnant cows (cycling cows) due to increased metabolic activity and physiological changes for foetal development following higher feed intake (Kendall and Webster, 2009).

In our study, the ruminal temperature gradually decreased before parturition. Cooper-Prado et al. (2011) reported that the decreased ruminal temperature before parturition was attributable to abnormal feeding rates and endocrine changes via secretion of hormones during pregnancy.

\section{CONCLUSION}

The dramatic change in the ruminal temperature of pregnant cows is interesting because this is the first study to monitor the real-time pattern of ruminal temperature and its differences between pregnant cows and nonpregnant cows. Therefore, the ruminal temperature in pregnant cows were found to significantly vary at four different periods of pregnancy. We believe that our findings will provide useful information for early detection of pregnancy and parturition in Korean cows.

\section{CONFLICTS OF INTEREST}

No potential conflict of interest relevant to this article was reported.

\section{ACKNOWLEDGEMENTS}

This work was supported by the Gyeongbuk Provincial Government through the R\&D vitalization project for agriculture, a project entitled "Development of a standard model of Gyeong-buk Hanwoo smart farm using real-time body temperature and its practical application".

\section{AUTHOR CONTRIBUTIONS}

Conceptualization: Dae Hyun Kim, Jae Jung Ha, Yoonseok Lee Data curation: Seung Ho Kim, Yoonseok Lee

Formal analysis: Dae Hyun Kim, Jae Jung Ha, Jun Koo Yi Funding acquisition: Bong-Hae Ye, Byung Ki Kim, WooSung Kwon

Investigation: Dae Hyun Kim, Jae Jung Ha

Methodology: Dae Hyun Kim, Woo-Sung Kwon, Yoonseok Lee Project administration

Resources: Gyeongbuk Provincial Government

Software: Seung Ho Kim, Yoonseok Lee

Supervision: Yoonseok Lee

Validation: Seung Ho Kim, Yoonseok Lee

Visualization: Seung Ho Kim, Yoonseok Lee

Writing - original draft: Dae Hyun Kim, Yoonseok Lee

Writing - review \& editing: Dae Hyun Kim, Yoonseok Lee

\section{AUTHOR'S POSITION AND ORCID NO.}

DH Kim, PhD, https://orcid.org/0000-0002-4820-4438

JJ Ha, $\mathrm{PhD}$, https://orcid.org/0000-0001-6785-6346

JK Yi, PhD, https://orcid.org/0000-0003-2593-6529

BK Kim, PhD, https://orcid.org/0000-0003-3127-6643

WS Kwon, Professor, https://orcid.org/0000-0002-0848-7189

BH Ye, BS, https://orcid.org/0000-0002-7941-2053

SH Kim, BS, https://orcid.org/0000-0003-1334-0154

Y Lee, Professor, https://orcid.org/0000-0003-4803-5192

\section{REFERENCES}

Ammer S, Lambertz C, von Soosten D, Zimmer K, Meyer U, Dänicke S, Gauly M. 2018. Impact of diet composition and temperature-humidity index on water and dry matter intake of high-yielding dairy cows. J. Anim. Physiol. Anim. Nutr. (Berl.) 102:103-113.

Bewley JM, Grott MW, Einstein ME, Schutz MM. 2008. Impact of intake water temperatures on reticular temperatures of lactating dairy cows. J. Dairy Sci. 91:3880-3887. 
Burfeind O, Suthar VS, Voigtsberger R, Bonk S, Heuwieser W. 2011. Validity of prepartum changes in vaginal and rectal temperature to predict calving in dairy cows. J. Dairy Sci. 94:5053-5061.

Cooper-Prado MJ, Long NM, Wright EC, Goad CL, Wettemann RP. 2011. Relationship of ruminal temperature with parturition and estrus of beef cows. J. Anim. Sci. 89:1020-1027.

Gasteiner J, Guggenberger T, Häusler J, Steinwidder A. 2012. Continuous and long-term measurement of reticuloruminal pH in grazing dairy cows by an indwelling and wireless data transmitting unit. Vet. Med. Int. 2012:236956.

Gasteiner J, Horn M, Steinwidder A. 2015. Continuous measurement of reticuloruminal $\mathrm{pH}$ values in dairy cows during the transition period from barn to pasture feeding using an indwelling wireless data transmitting unit. J. Anim. Physiol. Anim. Nutr. (Berl.) 99:273-280.

Gil Z, Kural J, Szarek J, Wierzchoś E. 2001. Increase in milk and body temperature of cows as a sign of embryo entry into the uterus. Theriogenology 56:685-697.

Higaki S, Miura R, Suda T, Andersson LM, Okada H, Zhang Y, Itoh T, Miwakeichi F, Yoshioka K. 2019. Estrous detection by continuous measurements of vaginal temperature and conductivity with supervised machine learning in cattle. Theriogenology 123:90-99.

Kendall PE and Webster JR. 2009. Season and physiological status affects the circadian body temperature rhythm of dairy cows. Livest. Sci. 125:155-160.

Kim H, Oh S, Ahn S, Choi B. 2017a. Real-time monitoring method of cattle's temperature for FMD prevention and its case studies. J. Korean Inst. Inf. Technol. 15:141-150.

Kim H, Oh S, Ahn S, Choi B. 2017b. Real-time temperature monitoring to enhance estrus detection in cattle utilizing ingestible bio-sensors: method \& case studies. J. Korean Inst. Inf. Technol. 15:65-75.

Lee Y, Bok JD, Lee HJ, Lee HG, Kim D, Lee I, Kang SK, Choi YJ. 2016. Body temperature monitoring using subcutaneously implanted thermo-loggers from Holstein steers. AsianAustralas. J. Anim. Sci. 29:299-306.

Ricci A, Racioppi V, Iotti B, Bertero A, Reed KF, Pascottini OB, Vincenti L. 2018. Assessment of the temperature cut-off point by a commercial intravaginal device to predict parturition in Piedmontese beef cows. Theriogenology 113:27-33.

Sakatani M, Sugano T, Higo A, Naotsuka K, Hojo T, Gessei S, Uehara H, Takenouchi N. 2018. Vaginal temperature measurement by a wireless sensor for predicting the onset of calving in Japanese Black cows. Theriogenology 111:19-24

Scanavez ALA, Fragomeni B, Rocha L, Voelz BE, Hulbert LE, Mendonça LGD. 2017. Association between 4-day vaginal temperature assessment during the dry period and performance in the subsequent lactation of dairy cows during the warm season. J. Anim. Sci. 95:5208-5217.

Suthar VS, Burfeind O, Bonk S, Dhami AJ, Heuwieser W. 2012. Endogenous and exogenous progesterone influence body temperature in dairy cows. J. Dairy Sci. 95:2381-2389.

Villot C, Meunier B, Bodin J, Martin C, Silberberg M. 2018. Relative reticulo-rumen $\mathrm{pH}$ indicators for subacute ruminal acidosis detection in dairy cows. Animal 12:481-490. 